\title{
Perspective
}

PERSPECTIVE Actualité en histoire de l'art

$4 \mid 2006$

La monographie d'artiste

\section{La monographie, un outil indispensable}

\section{Pierre Rosenberg}

\section{OpenEdition}

\section{Journals}

Édition électronique

URL : http://journals.openedition.org/perspective/4215

DOI : 10.4000/perspective.4215

ISSN : 2269-7721

Éditeur

Institut national d'histoire de l'art

Édition imprimée

Date de publication : 31 décembre 2006

Pagination : 497-498

ISSN : 1777-7852

\section{Référence électronique}

Pierre Rosenberg, «La monographie, un outil indispensable », Perspective [En ligne], 4 | 2006, mis en ligne le 31 mars 2018, consulté le 01 octobre 2020. URL : http://journals.openedition.org/perspective/ 4215 ; DOI : https://doi.org/10.4000/perspective.4215 


\section{La monographie, un outil indispensable}

Federico Zeri - je n'ai hélas pas sous les yeux la citation exacte - disait qu'on peut se consacrer à l'histoire de l'art que l'on veut, celle par laquelle on se sent attiré - iconographie, collectionnisme, psychologie ou sociologie de l'art, esthétique, sémiologie, histoire de l'histoire de l'art, réflexion théorique, que sais-je encore -, si l'on a rédigé une monographie, mais que l'on ne peut se prétendre historien d'art, quel que soit le champ que l'on s'est choisi, si l'on n'a pas écrit une monographie. Cette déclaration péremptoire quelque peu provocatrice - qui s'en étonnera venant de Federico Zeri ? - contient sa part de vérité.

Écrire la monographie d'un peintre, d'un sculpteur, d'un architecte, d'un cinéaste - je me limiterai ici aux périodes dites modernes et contemporaines - oblige celui qui l'entreprend à utiliser tous les instruments qui sont à la disposition du futur historien d'art. Il y a les archives et les bibliothèques, les photothèques privées ou publiques et les musées, réserves incluses. Il y a les cabinets de dessins et les grands fonds de gravures souvent insuffisamment consultés (qui sait par exemple que pour le catalogue raisonné d'un artiste français, la visite à la Bibliothèque nationale de France doit obligatoirement s'accompagner d'un déplacement à l'Albertina de Vienne ?). Il y a les collectionneurs et les marchands, les salles des ventes françaises et anglaises, petites et grandes. Il y a aujourd'hui Internet et le traitement de texte par ordinateur - indéniable progrès. Il y a la connaissance des langues vivantes bredouiller l'anglais ne suffit pas, l'allemand et l'italien restent obligatoires - et les langues dites mortes. Il y a les voyages et les détails matériels qu'il faut savoir maîtriser, commander une photographie, obtenir l'indispensable accès auprès du collectionneur revêche qui se cache et n'ouvre pas facilement sa porte. Il y a l'acquisition d'une pratique qui, dans l'avenir, s'avèrera indispensable.

Il y a surtout l'œeil... Car après tout, et on l'oublie aujourd'hui, l'histoire de l'art est une question d'œil. Celui qui se consacre à une monographie doit savoir réunir tout ce qui a été écrit et publié par le passé sur l'artiste de son choix mais il doit également intervenir, faire ses propositions tout en restant impartial, porter un jugement (je n'ai pas prononcé le mot " attribution", honni dans certains cercles universitaires).

Cette partie de sa tâche est la plus distrayante, la plus stimulante, elle oblige l'impétrant, comme on dit, à se plonger dans le monde vivant des musées et des marchands, à tenter d'en comprendre les mécanismes, elle oblige à lire et à regarder.

Vient ensuite la rédaction, l'austère rédaction. Quel plan adopter, comment rédiger une note, à quel moment l'auteur d'une monographie obligatoirement accompagnée d'un catalogue raisonné (autre mot honni) - une expression française adoptée dans toutes les langues - doitil prendre la parole à la première personne ? Que veut dire l'unification ? Comment rendre l'érudition vivante? Toutes ces questions, qui souvent ont découragé les plus vaillants et dont la maîtrise rend par la suite la vie de l'historien de l'art bien plus facile, sont clairement et méthodiquement abordées dans un article de Jacques Thuillier (paru dans le numéro de 
septembre-octobre 1975 de L'information d'histoire de l'art) dont je ne saurais trop recommander la lecture et dont je souhaiterais qu'il soit republié dans Perspective, un article qui évitera bien des tâtonnements.

On ne saurait aborder cette question des monographies sans faire allusion à leur coût. Pour l'auteur chevronné, guère de problèmes, la maison d'édition se chargera, surtout si l'artiste objet de cette monographie a quelque célébrité, d'en assurer les frais. Si l'artiste est moins connu et si aucun éditeur n'a eu le courage de se lancer dans l'aventure, il y a en France Arthéna (l'Italie est bien plus fortunée et une monographie même d'un artiste totalement oublié trouvera son éditeur). Mais le problème que nous voulons aborder ici est celui du débutant, qui ne dispose pas des indispensables ressources matérielles pour voyager, commander les photographies, etc... (et qui, souvent découragé, entreprend ce qu'il peut mener à bien sur place, avec la seule ressource d'une bibliothèque et de quelques photocopies). On ne saurait esquiver cette question (l'histoire de l'art est une discipline chère) qui mériterait, comme celle des droits de reproduction photographique pour laquelle l'horizon me paraît moins bouché qu'il y a encore quelques mois, une plus ample réflexion, objets de futurs éditoriaux de Perspective.

Revenons aux monographies. Elles redonnent vie à un artiste. Elles sont un révélateur. Elles permettent à leur auteur, en fonction de ses dispositions, de ses intérêts, de choisir sa voie. Elles lui donnent une liberté de manœuvre qui, on le constate si souvent à lire The Art Bulletin (un exemple parmi d'autres), manque à tant d'auteurs. Que de coquilles dans une citation en français, que de localisations erronées (un Gabriel de Saint-Aubin reproduit comme appartenant au Musée de Rouen, ce qui, hélas, n'est pas le cas). Que d'œuvres doctement commentées dont on sent bien que l'auteur ne les a jamais vues (et parfois on se demande si les avoir vues a pour cet auteur la moindre importance)... Certes, il n'y a pas de règles impératives dans la rédaction d'une monographie. Autant de monographies, autant de cas d'espèce et rien ne serait plus absurde que de vouloir en imposer. Mais il y a une méthode, celle d'une discipline scientifique que l'on appelle l'histoire de l'art. Comprendre l'importance d'un index, savoir mettre en ordre une bibliographie, bâtir méticuleusement une provenance, rédiger une notice de catalogue peut paraître inutilement minutieux, pour ne pas dire vain. Tout cela, entend-on dire, n'est que détails, dont seuls les tâcherons de la discipline s'occupent et se préoccupent.

Vivent les tâcherons. 